\title{
Polifonia narrativa como instrumento enigmático: estudo do romance A paz doméstica, de Teresa Veiga
}

\author{
Elisângela Aparecida Lopes \\ Mestre em Teoria da Literatura / UFMG
}

\begin{abstract}
RESUMO
O objetivo deste artigo é analisar o romance A paz doméstica, publicado em 1999 pela escritora portuguesa Teresa Veiga, a fim de destacar a polifonia narrativa como estratégia que compõe e fundamenta o enredo do referido romance. Por meio dessas estratégias e das referências literárias, torna-se possível ao leitor construir o perfil da personagem Dinora e depois, pela inserção de uma nova narradora, relativizá-lo, estabelecendo-se, assim, um enigma quanto à veracidade do narrado.
\end{abstract}

\section{PALAVRAS-CHAVE}

Teresa Veiga, referências literárias, narrador polifônico, enigma narrativo

“A arte, mesmo em segunda mão, é a grande consoladora dos males deste mundo". ${ }^{1}$

Neste artigo, pretendo analisar o perfil da narradora-protagonista do romance $A$ paz doméstica, da escritora portuguesa Teresa Veiga, a fim de destacar os aspectos narrativos da obra e as referências das artes plásticas e literárias nela contida. Antes, faz-se necessário um breve resumo desse romance, publicado em 1999.

A paz doméstica, narrado em primeira pessoa, conta a história de vida de uma família portuguesa, moradora de Viseu, Portugal, formada por Isabel Montalvão, jovem senhora, marcada pela elegância e pela manutenção das aparências sociais, a custo de um casamento fracassado; Manuel Luís, marido de Isabel, um professor universitário de

\footnotetext{
${ }^{1}$ VEIGA. A paz doméstica, p. 82.
} 
alemão, dado a uma vida mundana, marcada pelo adultério e pela resignação familiar; Hugo e Matilde, filhos dessa união. Os primeiros capítulos do romance oferecem-nos o perfil psicológico desses personagens, especialmente Matilde e Luis, por uma voz que, devido à descrição dos outros, configura-se como de terceira pessoa. Somente no capítulo IV, o foco de $1^{\mathrm{a}}$ pessoa se define devido à inserção da narradora na história: ela é Dinora, filha de Manuel Luís com Arminda, mulher simples que falece quando a filha ainda era pequena. Em virtude desse fato, Dinora é levada para a casa dos Montalvão, onde passa a residir, inserida numa família com a qual não se identifica, o que a faz se sentir “estrangeira”, sentimento que é compartilhado pelos demais.

O título do romance encontra-se repleto de ironia, já que essa “paz doméstica” não é alcançada, pois os integrantes dessa família são indiferentes uns aos outros, e esse sentimento afeta, principalmente, Dinora, a filha bastarda. Tal indiferença também se estabelece na relação entre Manuel Luís e os filhos Matilde e Hugo, marcada pelo enfrentamento por parte daquela e pela frieza, por parte deste, o que fazia com que o pai se sentisse em um campo de guerra: "entrincheirado nas suas posições.”² No entanto, Dinora e Hugo terão suas vidas interligadas não só pelos laços sanguíneos, mas também devido à manutenção de um segredo: Dinora tivera uma filha, fruto de uma relação temporária, e entrega essa filha ao irmão Hugo e à cunhada Beatriz, para que estes a criassem.

Dinora narra, nos dez capítulos do romance, a sua história de vida, marcada por algumas frustrações amorosas, por decepções familiares, mas por várias referências às artes plásticas e por um amor incondicional à literatura, especialmente os escritos de Stendhal. Os aspectos narrativos aos quais irei me deter se fazem presentes, no romance de Teresa Veiga, nas referências a obras de literatura e de artes plásticas, por parte de Dinora, indicando que o olhar dela para o mundo e para os seus é permeado pela Arte.

Uma das primeiras dessas referências se dá quando, em uma excursão da escola em que estudava, Dinora visita o Mosteiro de Santo Toríbio de Liébera, onde observou as reproduções das pinturas dos Códices de Santo Toríbio, o que a impressionou e proporcionou a ela se aproximar do Padre que acompanhava as alunas. Ela passa, então, a idealizar uma relação afetiva com esse padre, chegando a se referir a ele, na narração, como “meu padre”. Essa relação proibida incendeia os pensamentos de Dinora, por um curto momento, e a faz se lembrar do romance La regenta, de Clarín, publicado em

\footnotetext{
${ }^{2}$ VEIGA. A paz doméstica, p. 31.
} 
1885, um marco do realismo-naturalismo que narra a história de paixão entre D. Fermín, um padre e Ana, que encarna o "bovarismo” ante a uma sociedade hipócrita. Influenciada pelo meio e pelo gosto similar pela Arte, Dinora recria essa história ficcional aplicando-a à sua vida. Ao se despedir do padre, Dinora mistura ficção e realidade, ao fazer esta referência nominal a ele: “'Fermín!’ gritei, antes de cair por terra."3

Depois de sair da casa do pai e da madrasta, Dinora passa a viver em Lisboa, na casa de pensão de dona Simoneta. Esta, em um instinto materno, protege e cuida da protagonista quando a jovem adoece. Para amenizar sua tristeza diante da enfermidade, dona Simoneta pendura, no quarto de Dinora, a reprodução de alguns quadros feitos por um sobrinho. Um deles é o Batoteiro de ás de ouros, de Georges de La Tour.

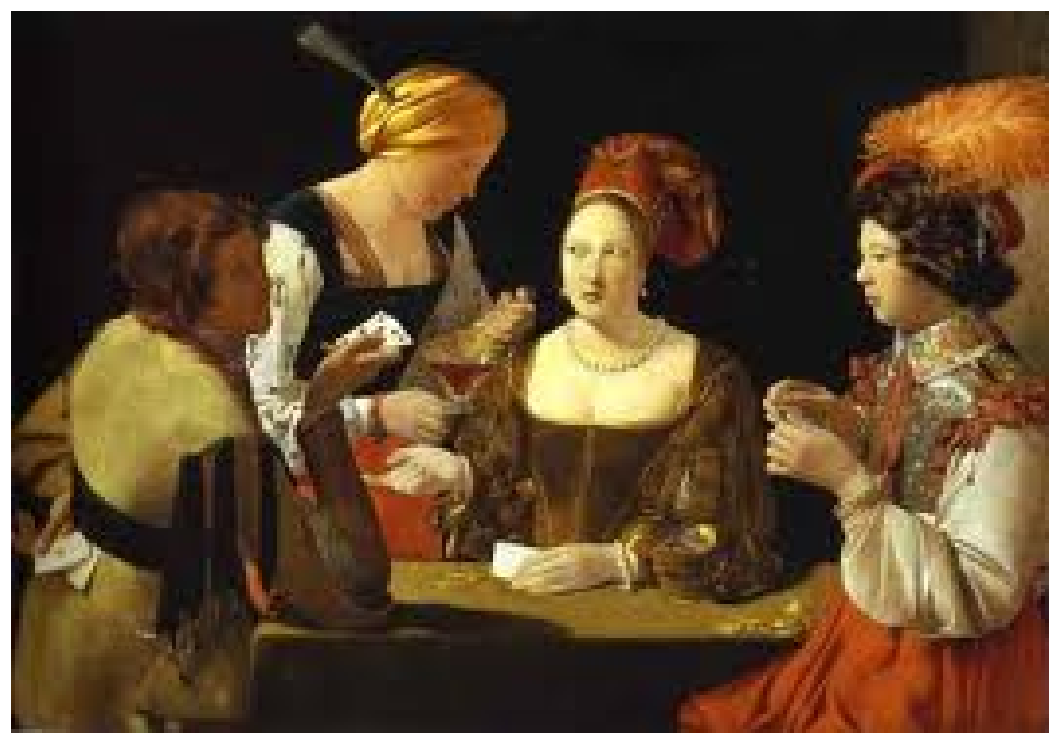

FIGURA 1: O Batoteiro de ás de ouro. Georg de La Tour (1635). Disponível em: $<$ http://obelogue.blogspot.com/2007/06/o-carteiro-faam-as-vossas-apostasveja.html>.

Nessa cena de um jogo de cartas, chama a atenção a atitude do personagem da esquerda que retira do cinto a carta que intitula o quadro. Esse personagem olha para o espectador do quadro colocando-o na posição de cúmplice de sua ação de trapacear, enquanto a personagem central aguarda a jogada do trapaceiro, dessa personagem destaca-se o olhar esgueirado. A referência ao quadro, no romance, se justifica pelo fato de dona Simoneta comparar o olhar de Dinora ao da personagem do quadro, apesar de não haver definição de à qual desses personagens a senhora se refere.

\footnotetext{
${ }^{3}$ VEIGA. A paz doméstica, p. 61.
} 
Outro quadro entregue pela senhora à protagonista é o Rapaz mordido por um lagarto, de Michelangelo Caravaggio.

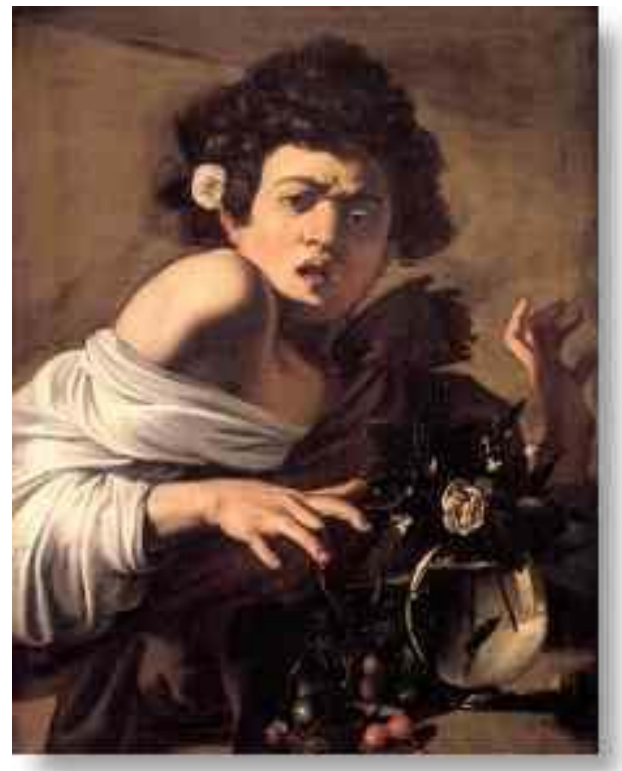

FIGURA 2: Rapaz mordido por um lagarto. Michelangelo Caravaggio (1595-96). Disponível em: < http://vestigialectionis2.blogspot.com/2007_01_01_archive.html>.

A interpretação do quadro exige uma reconstrução ficcional e descritiva por parte do espectador. O jovem rapaz, com ornamentos femininos, como a flor no cabelo, é surpreendido pela mordida de um lagarto que se encontra entre as flores do vaso. A repulsa quanto ao ocorrido fica a cargo da expressão facial e do movimento sugerido das mãos: a esquerda que se eleva, e a direita, cujos dedos estão retraídos de dor. A menção ao quadro, no livro de Teresa Veiga, talvez se refira a esse retraimento de Dinora, que dificulta a aproximação alheia.

As referências às obras literárias também são muitas no romance de Teresa Veiga. Destacamos algumas delas que nos auxiliam a compreender a visão de mundo de Dinora e, de alguma forma, a entender a construção narrativa desse romance. A primeira delas aprece ainda na infância da protagonista:

Já me referi a caderneta de cromos da Gata Borralheira e a emoção e o prazer estético que me deu a minha actividade de coleccionadora ao longo de meses. Lembro-me também de que num aniversário fiz sensação com um vestido de festa todo bordado que ele [o pai] me ofereceu, o qual havia de ser rasgado em tiras por Isabel Montalvão no auge de uma fúria em que suspeitou que a delicadeza do bordado era obra de amante. ${ }^{4}$

\footnotetext{
${ }^{4}$ VEIGA. A paz doméstica, p. 33.
} 
A presença de Dinora na casa da família Montalvão é indesejada. Em virtude disso, a menina se compara à Gata Borralheira, pois não se sente integrada à família; é a enjeitada que, por um breve momento, quando se sente parte desta, em virtude da roupa que usava, tem esse sonho desfeito pela figura da madrasta. Desse trecho, faz-se necessário ainda destacar a herança do pai: Dinora se apaixona pelo colecionismo e guarda com carinho os livros que lê; descobre uma coleção de postais alemães deixados pelo pai; e deixa à filha a coleção dos livros de Stendhal.

Dinora passa a estudar no Liceu feminino, e essa mudança provoca na protagonista uma impressão nova do mundo real e do universo literário. Nessa instituição, ela é aluna de Marie de St. Ange, uma mulher cuja inteligência e intelectualidade atraem a protagonista. Nesse Liceu, descobre a existência de novos livros de literatura indicados por St. Ange:

Ler os livros de que ela falava, andar pelos sítios por onde ela andava à espera de sentir as mesmas emoções, tornou-se a ocupação preferida e o principal objetivo da vida das suas admiradoras mais fiéis. Esses livros eram muito diferentes das obras que nos aconselhava a professora de português, actuavam como uma droga leve e como tal eram consumidos na clandestinidade, com a consciência de se estar a praticar uma infração, um delito sexual que tinha raízes nos desejos e recordações da infância. ${ }^{5}$

Essa passagem indica não só a fascinação que St. Ange causa na protagonista, como também aponta para a ideia da literatura como remédio a dar, aos leitores, um certo conforto, mas também como veneno, a viciá-los; em ambas as dosagens cabe à literatura transformar, seja de que forma for, o espírito e a vida do leitor, apontando para o conceito de remédio e veneno de que fala Derrida.

Dentre os livros indicados pela professora, destaca-se Le grand meaulnes, de Alain-Fournier, publicado em 1913, que narra a história de três jovens que vivenciam amores não correspondidos, encarnado, principalmente, pelo personagem Augustin Meaulnes ao traçar uma idealização amorosa e passar a narrativa a buscá-la. Essa mesma temática também se encontra presente em La Nunphe au cœur fidèle (1924), de Margaret Kennedy. A idealização amorosa, portanto, faz parte do universo das personagens dessas histórias literárias e, pela leitura, passa a habitar, também, a personalidade de Dinora.

\footnotetext{
${ }^{5}$ VEIGA. A paz doméstica, p. 49.
} 
Em virtude da presença referencial de algumas histórias literárias dentro do romance de Veiga, podemos afirmar que estamos diante de um romance cuja estrutura foi construída sob a perspectiva de mise en abyme. Tal conceito foi apontado pela primeira vez por Andre Gide, e o termo foi proposto por Claude Edmonde Magny, remetendo às construções artísticas nas quais se observa a reprodução do todo em uma parte que o compõem, como nas bonecas russas matrioskas ou no quadro Las meninas, de Velasquez.

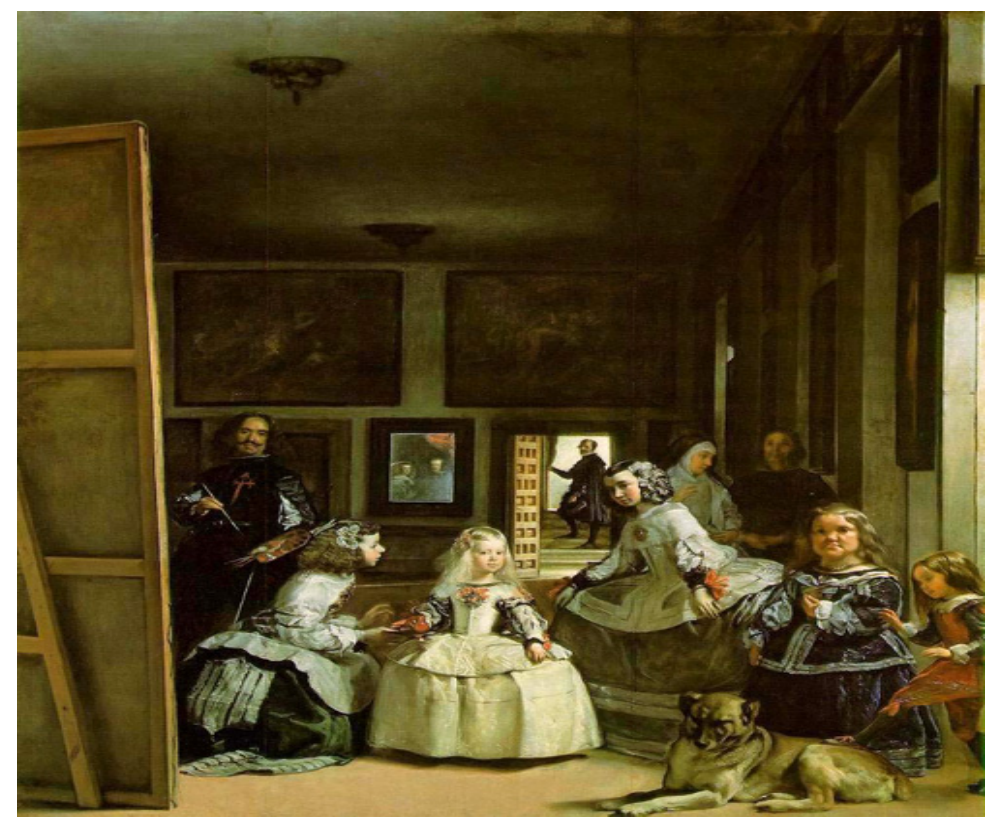

$\begin{array}{ccccc}\text { FIGURA } & \text { 3: } \\ & \text { Lhttp://www.sabercultural.org/template/obrasCelebres/AsMeninas.html>. }\end{array}$

Nesse quadro, em sua perspectiva de primeiro plano, tem-se o acesso aos “bastidores” da construção de um retrato de família. O pintor, do lado esquerdo, olha para frente e tem nas mãos os pincéis que usa para retratar o casal que se encontra em sua frente e que será retratado na tela que se encontra à esquerda do quadro. Enquanto isso, as crianças e os anões intentam convencer a criança a integrar a sua família e posar para o pintor.

Em segundo plano, percebemos que o casal a ser retratado encontra-se à frente da cena, pois está refletido no espelho ao fundo, mas também tal papel pode ser ocupado pelo próprio espectador do quadro, que assistiria a esses bastidores. Há ainda, ao fundo, um homem que deixa a cena, sendo que todos estão a olhar para o casal aristocrático ou para o espectador. Tem-se, portanto, conforme Guide, a representação de um quadro dentro do quadro, o que configura, na pintura, o mis en abyme. 
Tal recurso, presente nas Artes Plásticas, na Literatura, no Cinema, também nomeado "perspectiva em abismo” ou "composição em abismo", consiste, segundo Moisés, "na reprodução do objeto estético em tamanho menor: mirando o todo, o olhar converge para o detalhe que o reproduz. Fixando a retina no pormenor, tem-se a súmula reveladora da totalidade em que se inscreve.”6 Diante disso, poderíamos dizer que o leitor, ao mirar seu olhar para as referências literárias contidas nessa obra, tem acesso aos fundamentos da visão de mundo da narradora-protagonista, e conclui o quanto sua vida está colada às obras artísticas que cita ao narrar a sua história.

Dinora, enquanto jovem leitora, cuja visão de mundo já era marcada pela desestruturação afetiva de sua família, busca um universo outro, de sonhos e amores, nos livros indicados pela professora. Mais tarde, já adulta, tal idealização poderá justificar, ainda, os seus envolvimentos afetivos, suas frustrações e inventividade, quer seja no encantamento que Andreas, um leitor dos clássicos, provoca nela; quer seja sua ingenuidade quanto a Firmino - uma espécie de estelionatário -, que chantageia Hugo e Beatriz, tendo como trunfo o segredo dessa família: a filha de Dinora, que é criada pelo irmão e a pela cunhada.

Ainda quanto às obras literárias citadas no romance em questão, tem-se em “Fermina Marquez”, conto de Valéry Larbaud, a história da personagem que dá título à narrativa, uma jovem capaz de despertar fantasias nos alunos da escola. Já em Le tour d'écrou (A volta do parafuso), encontramos elementos da literatura fantástica presentes na história de uma governanta incumbida de cuidar de duas crianças assombradas por espíritos. Tal função é, inclusive, desempenhada por Dinora quando esta passa a viver, na Alemanha, na casa de Andreas. A história presente em Le pays ou l'on n'arrive jamais, romance de André Dhôtel, ${ }^{7}$ aponta para a ideia de travestimento e busca familiar, por narrar a vida de Gaspard, que conhece um menino que busca sua mãe, sendo que, ao final da história, Gaspard descobre que o amigo é, na verdade, uma menina, Hélène.

Na avaliação da narradora-personagem, entretanto, essa correspondência entre a vida presente nos romances e a sua própria não fica tão evidenciada assim, nem mesmo para o leitor, pois este não tem acesso aos detalhes, nem mesmo superficialmente, dos romances em questão. Eles são apenas referenciados na obra de Veiga pelos títulos.

\footnotetext{
${ }^{6}$ MOISÉS. Dicionário de termos literários, p. 297-298.

${ }^{7}$ DHÔTEL. Le pays ou l'on n'arrive jamais.
} 
Sendo assim, a procura por essas obras é que vai proporcionar ao leitor um melhor entendimento do enredo de A paz doméstica, do perfil da protagonista e, posteriormente, possibilitar o entendimento do último capítulo da obra.

Ainda quanto à narratividade do romance, alguns recursos empregados chamam a atenção do leitor. Um deles é a antecipação dos fatos. Como narradora de sua própria história, Dinora dá pistas sobre os desenrolar dos fatos, especialmente quando se trata do fracasso de suas relações afetivas. É o que acontece com a chegada do Sr. Niklas, um alemão disposto a negociar os cards - espécies de postais - que Dinora herdara do pai. A protagonista passa a vislumbrar um possível interesse desse homem em relação a ela. No nível da enunciação, antecipa o desfecho, ao afirmar: "veremos como a minha vaidade foi castigada, um castigo cruel, brutal e imerecido"; ${ }^{8}$ essa vaidade foi correspondida com o roubo cometido pelo visitante.

Outro aspecto importante é o uso pela narradora de expressões e termos próprios do universo ficcional quando se refere aos fatos por ela vividos. Para ela, cada vivência é entendida como um capítulo dessa sua autobiografia. Além disso, podemos destacar algumas referências a termos próprios da literatura, tais como: capítulos, para se referir aos fatos vividos; a clara referência às fantasias que nutria em relação à velhice; a atribuição de características de ficcionista a Andreas, o pai de sua filha; só para citar algumas pistas textuais.

Andreas exerce sobre a protagonista uma certa atração, devido, a princípio, à intelectualidade que aparenta ter, ao hábito de leitura dos clássicos que cultiva. Posteriormente, o personagem revela uma personalidade atormentada, dada à ficcionalização da vida, características que Dinora considera como indícios de esquizofrenia: “Diabólico e dotado de uma imaginação perversa para fabricar uma história com aparência de verdadeira sobre fracos indícios e confundi-la com a realidade em vez de aproveitar a veia romanesca a dedicar-se a escrever livros de ficção.”9 Imaginação fértil, aproximação entre realidade e imaginação são, posteriormente, características atribuídas pela filha a Dinora, sendo que para a jovem o que a mãe fez foi, por meio dos manuscritos, ficcionalizar a própria vida.

O último capítulo do romance de Teresa Veiga pode ser entendido como um suplemento, no sentido derridadiano do termo, pois seu conteúdo relativiza o relato

\footnotetext{
${ }^{8}$ VEIGA. A paz doméstica, p. 139.

${ }^{9}$ VEIGA. A paz doméstica, p. 122.
} 
autobiográfico construído por Dinora nos capítulos anteriores. A narradora da última parte do romance é a filha de Dinora e Andreas, criada por Hugo e Beatriz. A polifonia, entendida, conforme Bakthin $^{10}$, como a multiplicidade de vozes proveniente de consciências imissíveis, se manifesta em A paz doméstica por meio dessa nova narradora. Ela recupera indícios textuais lançados por Dinora em sua autobiografia, à qual a filha tem acesso após a morte da mãe. Ao ler esses manuscritos, a jovem aponta a relação imbricada entre ficção e realidade, deixando claro que os problemas mentais da mãe levaram-na a construir uma história que gostaria de ter vivido, marcada pelas referências aos livros de literatura aos quais teve acesso.

A relação entre o lido e o que se imaginou viver, portanto, a relação entre literatura e recriação da realidade do leitor, só é percebida quando temos acesso à narração da filha de Dinora, que fica responsável por desautorizar a história da mãe, a quem teve pouco acesso, ao afirmar, primeiro pela voz alheia - da tia -, depois por sua própria, que a mãe sofria de problemas mentais.

Michael Foucault, em A ordem do discurso, aponta a relação entre discurso e poder ao comentar:

A produção do discurso é ao mesmo tempo controlada, selecionada, organizada e redistribuída por certo número de procedimentos que têm por função conjurar seus poderes e perigos, dominar seu acontecimentos aleatório, esquivar sua pesada e remível materialidade. $^{11}$

Os métodos externos de controle do discurso, segundo o filósofo, seriam a interdição, na qual se insere, por exemplo, o tabu; a separação e a rejeição, exemplificada pelo lugar de fala do louco; a oposição verdadeiro e falso, apontadas como arbitrárias e/ou organizadas em torno de contingências históricas. Desses procedimentos, destacamos a interdição dos relatos de Dinora pela filha ao atribuir àquela a construção de uma vida fantasiosa, inclusive apontando a criação por parte da mãe de pessoas que não existiram, o que indicaria a construção de uma autobiografia ficcionalizada.

Foucault, no referido livro, aponta ainda os procedimentos internos de controle do discurso, “já que são os discursos eles mesmos que exercem seu próprio controle”, 12 os quais englobariam o comentário, por meio do qual se intenciona “dizer enfim o que

\footnotetext{
${ }^{10}$ BAKHTIN. Problemas da poética de Dostoiévski.

${ }^{11}$ FOUCAULT. A ordem do discurso, p. 9.

${ }^{12}$ FOUCAULT. A ordem do discurso, p. 21
} 
estava articulado no texto primeiro"; ${ }^{13}$ a noção de autoria, já que é entendido como um princípio argumentativo e índice de coerência. Ambos os procedimentos são levados a cabo pela filha de Dinora, ao construir um “apêndice” às histórias da mãe, visto que o último capítulo de A paz doméstica poderia ser assim entendido. Os comentários dessa narradora jogam por terra a história materna, apontando nela a inverossimilhança que passa despercebida pelo leitor, em virtude da existência de um pacto ficcional, conforme sintetiza Umberto Eco:

A norma básica para se lidar com uma obra de ficção é a seguinte: o leitor precisa aceitar tacitamente um acordo ficcional, que Coleridge chamou "suspensão da descrença". O leitor tem de saber que o que está sendo narrado é uma história imaginária, mas nem por isso deve pensar que o escritor está contando mentiras. ${ }^{14}$

Por outro lado, os relatos de Dinora, mesmo que sejam frutos de sua confusão mental, ocupam um papel importante na narrativa, pois é por meio deles que se tem acesso a um procedimento discursivo de relativização da instituição familiar, exemplificando o que Foucault comenta em relação ao papel do louco na ordem discursiva: “desde a Alta Idade Média, o louco é aquele cujo discurso não pode circular como o dos outros: pode ocorrer que sua palavra seja considerada nula e não seja acolhida, não tendo verdade nem importância.” ${ }^{15}$ Por essa razão, causa incômodos. Por isso ainda é na reclusão da casa de Algodor, a produzir seus manuscritos, que Dinora passar o fim de sua existência. A circulação dos conteúdos dessas páginas chega ao leitor e só no fim do livro são desautorizados pela voz (ressentida?) da filha da protagonista.

Quanto ao produtor de ficção, ou autor de literatura, Foucault atribui uma função peculiar: dar “à inquietante linguagem da ficção suas unidades, seus nós de coerência, sua inserção no real”. ${ }^{16} \mathrm{O}$ teórico aponta ainda uma terceira categoria de controle do discurso assentada nas regras que definem as condições de funcionamento discursivo: “ninguém entrará na ordem do discurso se não satisfizer a certas exigências ou se não for, de início, qualificado para fazê-lo.»17

\footnotetext{
${ }^{13}$ FOUCAULT. A ordem do discurso, p. 25.

${ }^{14}$ ECO. Seis passeios pelos bosques da ficção, p. 81.

${ }^{15}$ FOUCAULT. A ordem do discurso, p. 13.

${ }^{16}$ FOUCAULT. A ordem do discurso, p. 28.

${ }^{17}$ FOUCAULT. A ordem do discurso, p. 37.
} 
Do ponto de vista da influência das Artes Plásticas na visão de mundo da protagonista, destacamos o desejo desta de fazer parte, literalmente, de uma obra de arte, deixando a realidade para passar a integrar a construção artística, como forma de sobrevivência e/ou perenidade, pois, conforme consta na epígrafe deste artigo, retirada do romance de Teresa Veiga, a arte exerce o papel de consolar as dores humanas e, até mesmo, dirimir as mazelas da existência. Dinora afirma isso ao, adoentada, receber a reprodução dos quadros feita pelo sobrinho de dona Simoneta: “a verdade é que nunca mais me deixara abater pela aborrecimento causado pela doença e até me acontecia sonhar com as figuras das pinturas ou viver a ilusão de entrar pelo quadro adentro.”18

Enquanto autobiografia ficcionalizada, os escritos de Dinora entrariam nessa ordem do discurso literário, pois a autora desses relatos tem domínio de certos recursos literários e narrativos que chegam ao seu conhecimento por meio da leitura dos clássicos da literatura universal, sobretudo francesa. O desejo que Dinora infere em relação à St. Ange, o de construir uma “As confissões de Marie St. Ange”, 19 é ela quem faz em relação à própria vida ao construir os relatos de Dinora, posteriormente desautorizados pelo discurso da filha. Quanto a este, há ainda um nó a desvendar: não seria tal desautorização fruto do ressentimento da filha em relação ao abandono da mãe? Constitui-se nessa ambiguidade, que leva à ausência de um final fechado para o romance construído por Teresa Veiga, a construção de um enigma ficcional e a configuração de uma obra aberta, conforme definiu Umberto Eco. ${ }^{20}$

\section{RESUMO}

The objective of this article is to analyze the novel A paz doméstica, published in 1999, by the Portuguese writer Teresa Veiga, in order to highlight the narrative poliphony as a strategy to construct the plot of the novel. By means of narrative strategies, it is possible for the reader to devise the role of the character Dinora and later, by the insertion of a new narrator, to relativize it, establishing, thus, an enigma regarding the veracity of the story told.

\footnotetext{
${ }^{18}$ VEIGA. A paz doméstica, p. 82.

${ }^{19}$ VEIGA. A paz doméstica, p. 50.

${ }^{20}$ ECO. Seis passeios pelos bosques da ficção.
} 


\section{REFERÊNCIAS}

BAKHTIN, Mikhail. Problemas da poética de Dostoiévski. 2. ed. Trad. Paulo Bezerra. Rio de Janeiro: Forense Universitária, 1997.

CARVALHO, Elizabeth. O poder e o silêncio: chaves do discurso na ficção de Teresa Veiga. In: XI CONGRESSO INTERNACIONAL DA ABRALIC Tessituras, Interações, Convergências. Julho 2008 - Universidade de São Paulo - São Paulo, Brasil. Disponível em: <http://www.abralic.org.br/anais/cong2008/AnaisOnline/simposios/pdf/017/ELIZABET H_CARVALHO.pdf>. Acesso em: 20 de jul. 2011

DERRIDA, Jacques. A farmácia de Platão. 2. ed. Trad. Rogério Costa. São Paulo: Iluminuras, 1997.

DERRIDA, Jacques. Gramatologia. Trad. Miriam Schnaiderman e Renato Janine Ribeiro. São Paulo: Perspectiva/Editora Universidade de São Paulo, 1973.

DHÔTEL, Andre. Le pays ou l'on n'arrive jamais. França: J'ai Lu, 2001.

ECO, Umberto. Seis passeios pelos bosques da ficção. Trad. Hildegard Feist. São Paulo: Companhia das Letras, 1994.

FOUCAULT, Michael. A ordem do discurso. Trad. Laura Fraga de Almeida Sampaio. São Paulo: Iluminuras, 2009.

JAMES, Henry. Os inocentes: a volta do parafuso. Trad. Cláudia Lopes. São Paulo: Scipione, 1986.

JAMES, Henry. A volta do parafuso. Trad. Francisco Carlos Lopes. São Paulo: Landmark, 2004.

MOISÉS, Massaud. Dicionário de termos literários. São Paulo: Cultrix, 2004.

VEIGA, Teresa. A paz doméstica. Lisboa: Cotovia, 1999. 